\title{
Paciente con botriomicosis pulmonar primaria confundida con actinomicosis: una mortal e infrecuente enfermedad infecciosa
}

\section{A patient with primary pulmonary botryomycosis mistaken with actinomycosis: a lethal and uncommon infectious disease}

\section{Correspondencia \\ Mayron D. Nakandakari \\ mayron.nakandakari@outlook.com}

\section{Recibido: 03/06/2018}

Arbitrado por pares

Aprobado: 05/09/2018

Citar como: Nakandakari MD, De La Rosa DN, Gutiérrez JL, Bryson W. Paciente con botriomicosis pulmonar primaria confundida con actinomicosis: una mortale infrecuente enfermedad infecciosa. Acta Med Peru. 2018;35(4):233-8
Mayron D. Nakandakari ${ }^{1, a}$, Dyanne N. De La Rosa ${ }^{1, a}$, Jorge L. Gutiérrez ${ }^{2, b}$, Walter Bryson ${ }^{3, c}$

1 Universidad Privada San Juan Bautista. Lima - Perú.

2 Departamento de Neumología. Hospital Nacional Hipólito Unanue. Lima - Perú.

3 Unidad de Cuidados Intensivos. Hospital Nacional Hipólito Unanue. Lima - Perú.

a Médico cirujano, b Médico Neumólogo, c Médico Intensivista

\section{RESUMEN}

La botriomicosis es una mortal e infrecuente infección bacteriana granulomatosa supurativa. Presentamos el caso de una paciente de 52 años que reingresó por cuadro respiratorio complicado dos meses anteriores, con síntomas caracterizados por tos, disnea, alza térmica, inapetencia y pérdida de peso. En la tomografía pulmonar se observó fibrosis, infiltrado alveolar bilateral, cavidades y bronquiectasias bilaterales. La citología de aspirado bronquial mostró gránulos azurófilos haciendo sospechar de actinomicosis, por lo que se le dio tratamiento con penicilina, sin mejoría. En el segundo cultivo de aspirado bronquial el patólogo describió a dos grupos de colonias bacterianas gramnegativas de Escherichia coli, las cuales simularon gránulos azurófilos, planteándose como diagnóstico definitivo botriomicosis pulmonar por $E$. coli BLEE, no obstante, la paciente ya había fallecido. Como conclusión, se reporta una patología infecciosa de muy baja prevalencia, pero frecuentemente confundida con la Actinomicosis, cuyo diagnóstico temprano es extremadamente importante para reducir su alta mortalidad.

Palabras clave: Escherichia coli; Acinetobacter baumannii; Actinomicosis (fuente: DeCS BIREME).

\section{ABSTRACT}

Botryomycosis is a lethal and uncommon granulomatous and suppurative bacterial infection. We present the case of a 52-year old female patient who was readmitted because of a respiratory disease that became complicated. She had had cough, dyspnea, fever, loss of appetite, and weight loss. A pulmonary CT scan showed fibrosis, bilateral alveolar infiltrate, cavities, and bilateral bronchiectasis. Bronchial aspirate cytology showed azurophilic granules, leading to suspect a diagnoses of actinomycosis, so penicillin was started, but no improvement was observed. In the second culture of bronchial aspirate two groups of Gram-negative bacteria colonies resembling Escherichia coli were observed, but also images resembling azurophilic granules were found, so the definitive diagnosis proposed was pulmonary botryomycosis caused by BLEE E. coli; nonetheless, the patient had just passed away. As a conclusion, an infectious disease with a very low prevalence is reported, where an early diagnosis is extremely important in order to reduce its high lethality rate.

Keywords: Escherichia coli; Acinetobacter baumannii; Actinomycosis (source: MeSH NLM). 


\section{INTRODUCCIÓN}

La botriomicosis, también llamada bacteriosis granular, pseudomicosis bacteriana o actinofitosis estafilocócica ${ }^{[1]}$, es una enfermedad infecciosa, crónica y supurativa que puede afectar una gran variedad de órganos y tiene como agente infeccioso más común al Staphylococcus aureus; otros menos frecuentes son la Pseudomona aeruginosa, Escherichia coli, estreptococo $\beta$ hemolítico, Actinobacillus lignieresii, Moraxella, Serratia y Peptostreptococo ${ }^{[2]}$.

Su fisiopatología aún es desconocida, aunque se postula que habría un defecto inmune o una respuesta inusual del tejido afectado para contener a la bacteria ${ }^{[3]}$. Afecta mayormente a pacientes inmunocomprometidos, si bien se ha descrito algunos casos en pacientes inmunocompetentes ${ }^{[5]}$.

La prevalencia de la botriomicosis es muy baja, tanto que se reportaron solamente 26 casos alrededor del mundo ${ }^{[4]}$. Reportamos el caso de una paciente mujer adulta con botriomicosis de presentación pulmonar; cualidad que se caracteriza por ser altamente mortal si es detectada tardíamente y tener como principal diagnóstico diferencial a la actinomicosis.

\section{CASO CLÍNICO}

Paciente mujer de 52 años proveniente de la ciudad de Lima Perú, con antecedente de hipertensión arterial en tratamiento desde hace 10 años. Niega tabaquismo, alcoholismo, diabetes mellitus, asma, uso de corticoides, cirugías y VIH/SIDA.

Tres meses previos al ingreso acudió al hospital por presentar dificultad respiratoria, tos con expectoración blanquecina y sensación de alza térmica. Fue hospitalizada en el servicio de neumología en donde, mediante cultivo de aspirado bronquial, se obtuvo un antibiograma positivo para Escherichia coli BLEE ( $\beta$ lactamasa de espectro extendido). Fue trasladada a la Unidad de Cuidados Intensivos por dificultad respiratoria agravada, falla renal aguda y shock mixto hipovolémico-distributivo. Fue estabilizada y dada de alta voluntaria sin tener un diagnóstico definitivo tras una semana de hospitalización.

Al ingreso, la paciente acudió al servicio emergencia del hospital por presentar desde hace dos semanas hiporexia, disnea a medianos esfuerzos, fiebre no cuantificada, tos con expectoración blanquecina y disminución de peso de cinco kilogramos -a lo largo de los tres meses-, motivo por el que fue hospitalizada.

Durante la evaluación física se evidenció un tórax simétrico, con timpanismo conservado. A la auscultación se encontraron crepitantes difusos en ambos hemitórax. Los hallazgos en otros sistemas no fueron relevantes.

En la toma de exámenes auxiliares, tanto la radiografía de tórax (Figura 1) como tomografía pulmonar (Figura 2) mostraron signos de fibrosis pulmonar e infiltrado alveolar bilateral, con cavidades de aspecto bulloso y bronquiectásicas bilaterales a predominio de campo pulmonar izquierdo.

En el cultivo de aspirado bronquial se aislaron Escherichia coli BLEE y Acinetobacter baurmannii. La citología de la misma muestra fue positivo para actinomicosis pulmonar, además describía material necrohemorrágico con presencia de macrófagos alveolares, algunos con pigmento carbón, otros reactivos, eosinófilos, polimorfonucleares, linfocitos, células columnares desvitalizadas, gránulos azurófilos, células epiteliales sueltas escamosas necróticas, dos mantos de epitelio escamoso y escasas células redondas eosinófilas atípicas pequeñas (Tabla 1).

Se dispuso a iniciar el tratamiento para actinomicosis con penicilina $\mathrm{G}$ sódica a dosis de 20 millones de unidades/día divididas cada seis horas por cuatro semanas. No obstante, no hubo mejoría alguna y su sintomatología se agravó. Una segunda citología de aspirado bronquial postratamiento fue negativa para actinomicosis y neoplasia.

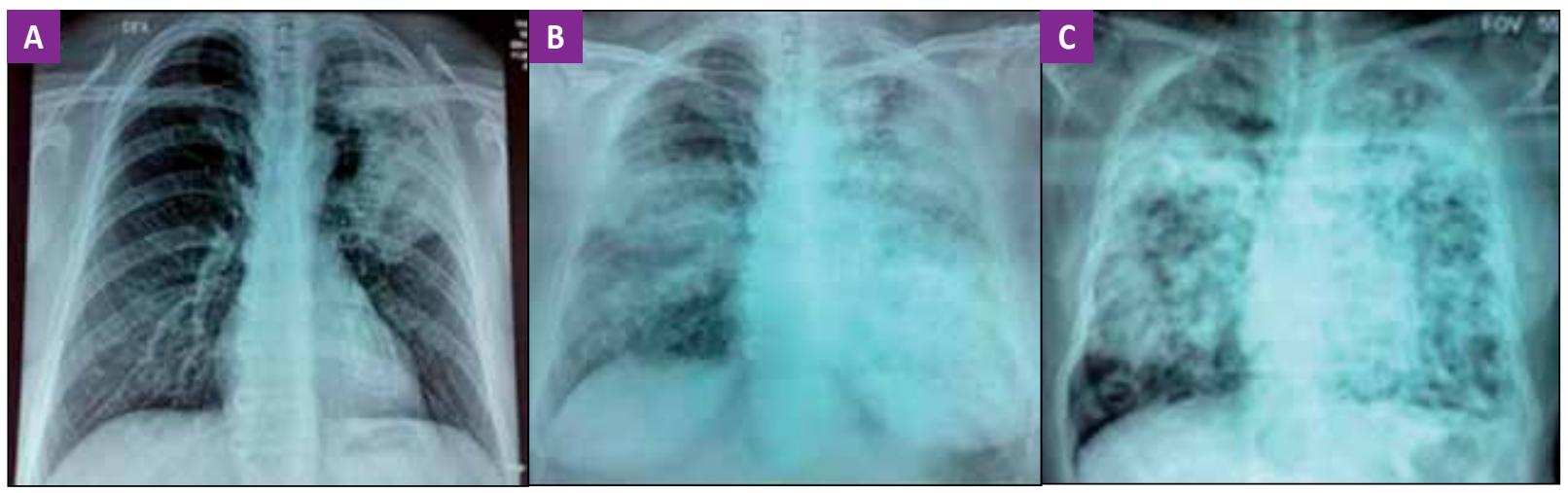

Figura 1. Radiografías de tórax postero-anterior. A. Primera hospitalización: se muestra infiltrado alveolar que compromete el lóbulo apical y medial del lado izquierdo. B. Tres meses después: fibrosis pulmonar e infiltrado alveolar bilateral con cavidades de aspecto bulloso y bonquiectásicos bilateral a predominio izquierdo. C. Cinco meses después: nódulos pulmonares múltiples, cavidades y bronquiectasias en ambos pulmones. El relato del caso parte de la segunda hospitalización ("tres meses después"). 

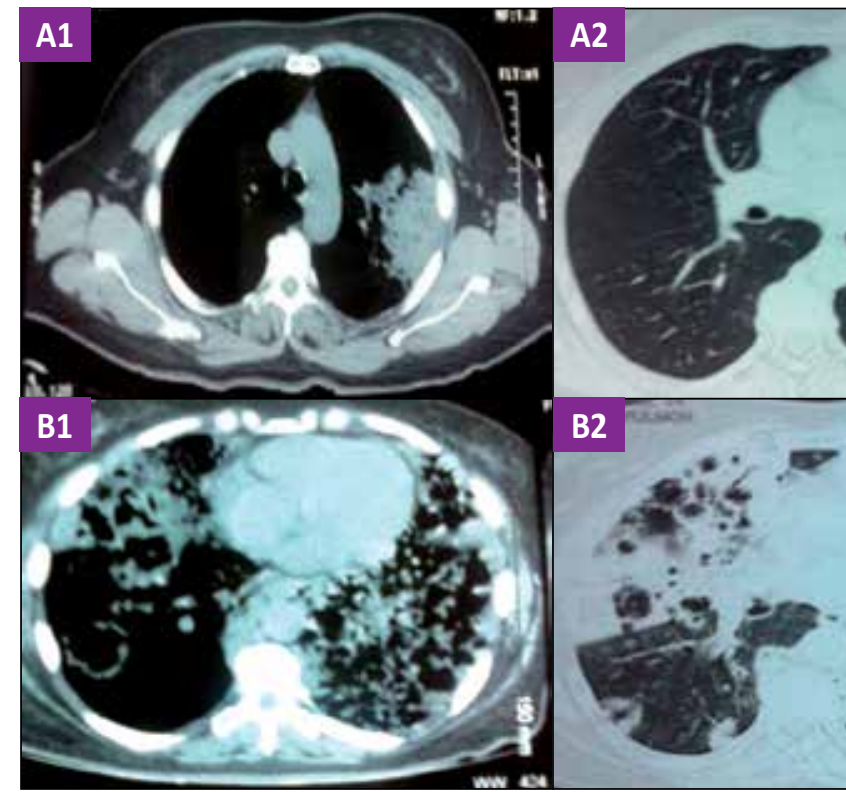

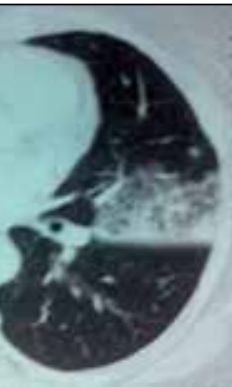

B2
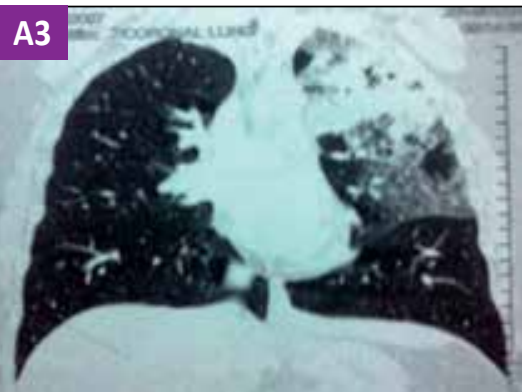

B3
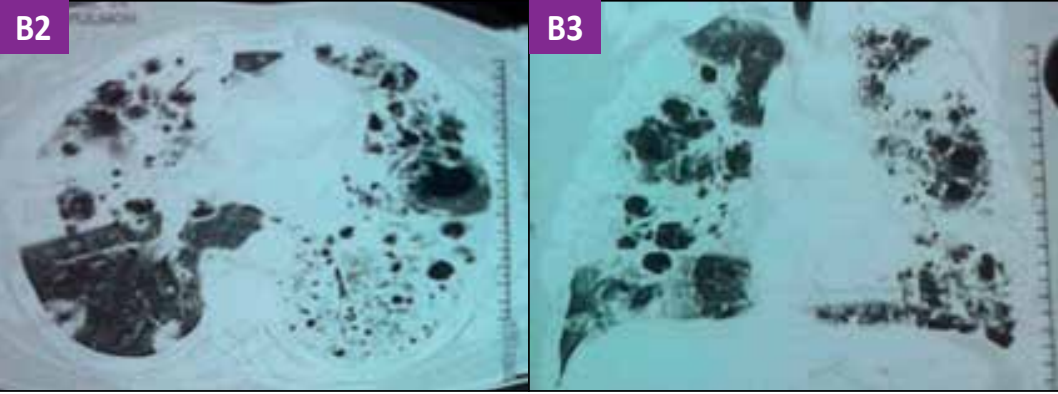

Figura 2. Tomografía computarizada (TC) pulmonar. A. TC de la primera hospitalización: (A1 y A2) ventana mediastinal, (A3) ventana para parénquima pulmonar; se visualizan nodulaciones cavitadas en la zona apical y medial del pulmón izquierdo. B. TC cinco meses después: (B1 y B2) ventana mediastinal, (B3) ventana para parénquima pulmonar, se presencian bronquiectasias y múltiples nódulos cavitados bilaterales.

Tras una junta médica se decidió iniciar tratamiento con fluconazol a dosis de $400 \mathrm{mg}$ por día, se indicó la revisión de láminas de la primera y segunda citología del aspirado bronquial y la realización de biopsia de parénquima pulmonar, que no se realizó por decisión de la paciente. Después de tres días de tratamiento, la paciente falleció por falla respiratoria hipoxémica y reagudización de su falla renal.

Una semana después del deceso se conoció el informe de la revisión de láminas, la cual describía que el bloque celular

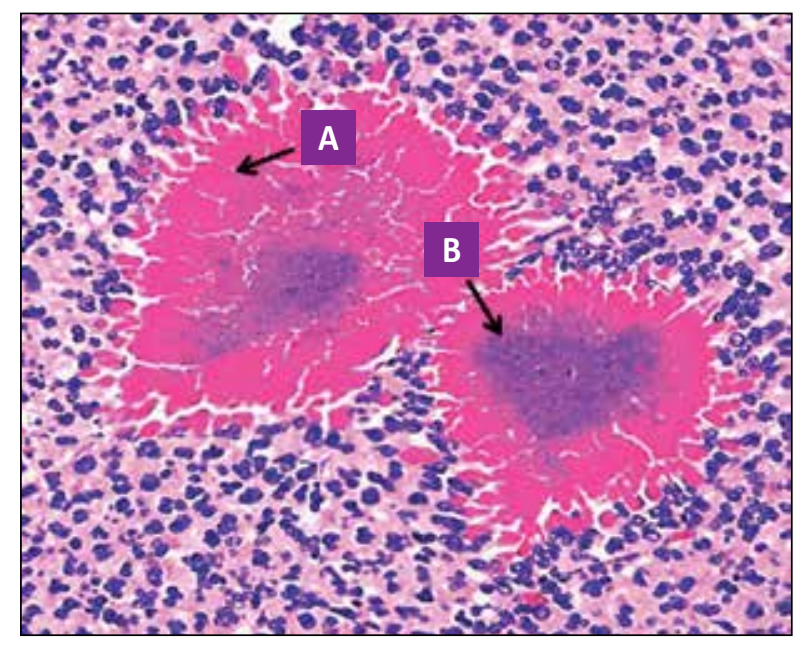

Fuente: los autores.

Figura 3: Citología de aspirado bronquial. Tinción Gram, aumento 10X. Descripción: (A) se observa el Fenómeno Splendore-Hoeppli. (B) Presencia de gránulos de Bollinger conformados por cúmulos de bacterias. mostraba un fondo fibrinoso con abundante cantidad de macrófagos espumosos, seguidos en proporción de grupos de células bronquiales que conservaban su forma en cepillo $y$, en menos cuantía, poblaciones celulares bronquiales con metaplasia escamosa e hiperplasia de las células de reserva; se acompañaba de leve a moderado componente inflamatorio conformado por neutrófilos, linfocitos y eosinófilos. Se observó dos pequeños grupos de colonias bacterianas gramnegativas que simularon los gránulos azurófilos de la actinomicosis (Figura 3). La anatomía patológica dio el diagnóstico definitivo de botriomicosis pulmonar debido a bacterias gramnegativas (Escherichia coli BLEE).

\section{DISCUSIÓN}

Algunos factores que aumentan la probabilidad de desarrollar botriomicosis son ${ }^{(6,7)}$ : alcoholismo, diabetes mellitus, infección por VIH, fibrosis quística, enfermedades granulomatosas crónicas, traumas y complicaciones quirúrgicas. A diferencia de reportes previos (Tabla 2), en nuestro caso no se pudo identificar un factor de riesgo específico que hubiese predispuesto a la inmunodeficiencia, antecedente clave permite realizar un diagnóstico temprano de la enfermedad.

Respecto a la clínica, se ha descrito sintomatología asociada como tos crónica, disnea, hemoptisis, y dolor torácico. A la evaluación clínica se suelen auscultar ruidos respiratorios disminuidos y presencia de crepitantes. Conforme progresa la sintomatología, la botriomicosis pulmonar va aumentando su mortalidad ${ }^{(8)}$. Nuestra paciente cursó con tos crónica y disnea; además, se pudo auscultar crepitantes en ambos campos pulmonares. 
Tabla 1. Pruebas de Laboratorio y sus Resultados.

\begin{tabular}{|c|c|}
\hline Pruebas de Laboratorio & Resultados \\
\hline Hemograma & $\begin{array}{l}\text { Serie blanca: leucocitos }\left(20200 \times \mathrm{mm}^{3}\right) \text {, neutrófilos }(80,7 \%) \text { linfocitos }(10,0 \%) \text { monocitos }(9,0 \%) \text {, } \\
\text { eosinófilos }(0,6 \%) \text {, basófilo }(0,2 \%) \text {. Serie roja: hemoglobina }(12,5 \mathrm{~g} / \mathrm{dl}) \text {, hematocrito }(35,5 \%), \mathrm{VCM}(78,2 \\
\mathrm{fL}), \operatorname{HCM}(26,9 \mathrm{pg}), \mathrm{CHCM}(34,4 \mathrm{~g} / \mathrm{dL}), \operatorname{ADE}(12,5 \%) \text {, plaquetas }\left(220.000 \mathrm{xm}^{3}\right) \text {. }\end{array}$ \\
\hline Pruebas bioquímicas & $\begin{array}{l}\text { Urea }(51 \mathrm{mg} / \mathrm{dL}) \text {, glucosa }(99 \mathrm{mg} / \mathrm{dL}), \text { ALT }(104 \mathrm{UI} / \mathrm{I}) \text {, AST (95 UI/I), fosfatasa alcalina (104 UI/I), GGT (686 } \\
\mathrm{UI} / \mathrm{I}) \text {, proteínas totales }(6 \mathrm{~g} / \mathrm{dL}) \text {, albúmina }(3.3 \mathrm{~g} / \mathrm{dL}) \text {, proteína } \mathrm{C} \text { reactiva }(4.97 \mathrm{mg} / \mathrm{dL}) \text {, creatinina }(0.78 \\
\mathrm{mg} / \mathrm{dL}) \text {, bilirrubina total }(0.60 \mathrm{mg} / \mathrm{dL}) \text { bilirrubina directa }(0.20 \mathrm{mg} / \mathrm{dL}) \text {, bilirrubina indirecta }(0.40 \mathrm{mg} / \mathrm{dL}) \text {. }\end{array}$ \\
\hline $\begin{array}{l}\text { Tinción en aspirado } \\
\text { bronquial }\end{array}$ & Tinción KOH (-). Tinción Gram negativa. \\
\hline $\begin{array}{l}\text { Cultivo de aspirado } \\
\text { bronquial }\end{array}$ & Positivo para Escherichia coli y diplococos gramnegativos. \\
\hline Antibiograma & $\begin{array}{l}\text { Escherichia coli resistente para ampicilina, ceftazidima, cloranfenicol. Sensible para amikacina, } \\
\text { gentamicina, trimetoprima/sulfametoxazol. }\end{array}$ \\
\hline Inmunodifusión & Aspergillus fumigatus (-), Histoplasma capsulatum (-) y Paracoccidioides brasiliensis (-). \\
\hline Otras pruebas & $\begin{array}{l}\text { VIH (no reactivo), BK en esputo }(-) \text {, Anti-GBM }(<1: 4) \text {, Anti-DNA (31), ANA (-), C3 (133), C4 (28), proteínas } \\
\text { A3 }(1,2) \text {, MPO }(3,6) \text {, ANCA (-). }\end{array}$ \\
\hline
\end{tabular}

VCM: volumen corpuscular medio; HCM: hemoglobina corpuscular media; CHCM: concentración de hemoglobina corpuscular media; ADE: amplitud de la distribución hereditaria; AST: aspartato aminotransferasa; ALT: alanina aminotrasferasa; GGT: gama glutamil transpeptidasa.

Entre los hallazgos radiológicos, frecuentemente se ha encontrado un patrón de fibrosis pulmonar e infiltrados reticulares opacos, con bronquiectasias que muestran un patrón en "panal de abeja"; patrones que también se encontraron en nuestra paciente.

Dada la poca frecuencia de presentación y la dificultad para lograr un diagnóstico definitivo (biopsia histopatológica coadyuvada por el cultivo microbiológico ${ }^{[9]}$, suelen considerarse previamente a otras enfermedades en el diagnóstico diferencial como la actinomicosis, nocardiosis, infecciones por hongos, tuberculosis y neoplasias pulmonares ${ }^{(10)}$.

De las anteriores, la botriomicosis pulmonar es más frecuentemente confundida con la actinomicosis pulmonar. Esto porque el hallazgo histopatológico de gránulos compuestos de masas bacterianas (granos de Bollinger) rodeadas de una matriz eosinofilica (fenómeno Splendore-Hoeppli) es confundido con los gránulos azurófilos o sulfurados de la actinomicosis ${ }^{[11)}$.

En pacientes con diagnóstico de actinomicosis pulmonar debe sospecharse la botriomicosis cuando haya un periodo terapéutico de tres semanas sin ninguna mejora, ya sea clínica o radiológica.

El tratamiento de elección para tratar la botriomicosis depende del tipo de bacteria que se identifique y puede ir desde un manejo médico hasta uno radical como una lobectomía. Nuestra paciente, a la que se le detectaron bacterias gramnegativas como la Escherichia coli, pudo haber sido medicada con ceftriaxona (1 a $2 \mathrm{~g}$ una vez al día), ciprofloxacino ( $400 \mathrm{mg}$ IV cada 12 horas), imipenem (500 mg IV cada 6 horas), o ertapenem ( 1 mg IV cada 24 horas) ${ }^{[12]}$.

No obstante, la Escherichia coli detectada era productora de BLEE, enzimas capaces de hidrolizar a las penicilinas, cefalosporinas (menos las cefamicinas) y los monobactámicos ${ }^{(12)}$; por lo cual, quedaban como alternativas la asociación de cefalosporinas con ácido clavulánico, sulbactam, tazobactam, imipenem o ertapenem.

A modo de conclusión, presentamos el reporte de un caso de botriomicosis con compromiso pulmonar que probablemente sea el primero en el país, el cual correspondió a una mujer de 52 años, aparentemente sin factores de inmunodepresión, cuyo agente etiológico fue la Escherichia coli BLEE y cuyo diagnóstico definitivo fue hallado post mortem.

Recomendamos considerar a la botriomicosis pulmonar dentro del diagnóstico diferencial, pues a pesar de ser una patología poco frecuente, su desconocimiento implica tanto el no tratamiento oportuno como el empeoramiento del pronóstico debido la alta mortalidad conforme se siga el curso natural de la enfermedad.

Así mismo, sugerimos considerar a la botriomicosis dentro del abanico de posibilidades etiológicas en aquellos pacientes con actinomicosis pulmonar ya que es frecuente la confusión histopatológica entre estas dos enfermedades y un diagnóstico no oportuno y precoz puede provocar un desenlace fatal.

Por último, recomendamos sospechar de botriomicosis siempre que se tenga como escenario a un paciente inmunocomprometido con una enfermedad pulmonar de evolución desfavorable, tal como en el presente caso.

Fuente de Financiamiento: Autofinanciado.

Conflictos de Interés: Los autores declaramos no tener conflictos de interés. 
Tabla 2. Resumen de 10 casos de botriomicosis pulmonar.

\begin{tabular}{|c|c|c|c|c|c|}
\hline $\begin{array}{c}\text { Año de } \\
\text { Reporte } \\
\text { [Referencia] }\end{array}$ & Edad/sexo & Antecedentes & Microbiología & Tratamiento & Evolución \\
\hline $1992^{[1]}$ & $19 / \mathrm{F}$ & $\begin{array}{l}\text { Neumonía lobar en la } \\
\text { niñez. }\end{array}$ & $\begin{array}{l}\text { Microscopía: gramnegativos } \\
\text { (Posibilidad: Pasteurella, } \\
\text { Corynebacterium, } \\
\text { Pseudomonas). }\end{array}$ & $\begin{array}{l}\text { Empíricamente: } \\
\text { gentamicina y nafcilina. }\end{array}$ & $\begin{array}{l}\text { Excelente respuesta } \\
\text { clínica a la terapia. }\end{array}$ \\
\hline $1994^{[2]}$ & $66 / F$ & Ninguno & $\begin{array}{l}\text { Microscopía: cocos } \\
\text { grampositivos. }\end{array}$ & $\begin{array}{l}\text { Cirugía (lobectomía) } \\
\text { y tratamiento } \\
\text { antibiótico endovenoso } \\
\text { con Clindamicina y } \\
\text { Ceftriaxona. }\end{array}$ & Resolución clínica. \\
\hline $1996^{[3]}$ & $36 / \mathrm{M}$ & $\begin{array}{l}\text { Fumador crónico, } \\
\text { infección severa del virus } \\
\text { del Papiloma Humano en } \\
\text { el pene, HIV positivo. }\end{array}$ & $\begin{array}{l}\text { Cultivo con crecimiento } \\
\text { de colonias grampositivas } \\
\text { (Probablemente } \\
\text { Stafilococo aureus). }\end{array}$ & $\begin{array}{l}\text { Amoxicilina/ácido } \\
\text { clavulánico por vía oral. }\end{array}$ & $\begin{array}{l}\text { Resolución clínica. } \\
\text { Presencia de Fibrosis } \\
\text { Pulmonar después de } \\
6 \text { meses. }\end{array}$ \\
\hline $1997^{[4]}$ & $67 / M$ & $\begin{array}{l}\text { Asma tratada con } \\
\text { corticoides inhalatorios, } \\
\text { fumador crónico, } \\
\text { hipotiroidismo, } \\
\text { hemigastrectomía por } \\
\text { úlcera péptica. }\end{array}$ & $\begin{array}{l}\text { Cultivo con crecimiento } \\
\text { de Pseudomona } \\
\text { aeruginosa. }\end{array}$ & $\begin{array}{l}2 \mathrm{~g} \text { de ceftazidima } \\
\text { intravenoso cada } \\
8 \text { horas de curso } \\
\text { prolongado. }\end{array}$ & $\begin{array}{l}\text { Paciente fue dado de } \\
\text { alta y falleció } 6 \text { meses } \\
\text { después sin evidencia } \\
\text { de recurrencia de las } \\
\text { lesiones pulmonares } \\
\text { radiográficamente. }\end{array}$ \\
\hline $2000^{[5]}$ & $63 / M$ & $\begin{array}{l}\text { Asma, apnea } \\
\text { obstructiva del sueño, } \\
\text { diabetes tipo II. } \\
\text { neumonía lobar en la } \\
\text { niñez. }\end{array}$ & $\begin{array}{l}\text { Examinación } \\
\text { microscópica de aspirado } \\
\text { bronquial revela cocos } \\
\text { grampositivos. }\end{array}$ & $\begin{array}{l}10 \text { días con antibióticos } \\
\text { endovenosos de alto } \\
\text { espectro: metronidazol, } \\
\text { benzilpenicilina, y } \\
\text { gentamicina. }\end{array}$ & $\begin{array}{l}\text { Resolución completa } \\
\text { radiográficamente a } \\
\text { los } 6 \text { meses. }\end{array}$ \\
\hline $2005^{[6]}$ & $62 / F$ & $\begin{array}{l}\text { Fumadora crónica, } \\
\text { osteoartritis, migrañas. }\end{array}$ & $\begin{array}{l}\text { Histología: presencia de } \\
\text { cocos grampositivos. }\end{array}$ & $\begin{array}{l}\text { Solo cirugía } \\
\text { (lobectomía). }\end{array}$ & Resolución clínica. \\
\hline $2008^{[8]}$ & $45 / M$ & Fumador crónico. & $\begin{array}{l}\text { Cultivo con crecimiento } \\
\text { de colonias grampositivas } \\
\text { y negativas. Cultivo de } \\
\text { muestra histológica } \\
\text { positivo para anaerobios: } \\
\text { Peptostreptococcus, } \\
\text { Actinomyces spp, y } \\
\text { Prevotella } \\
\text { intermedia. }\end{array}$ & $\begin{array}{l}\text { Antibioterapia de } \\
\text { amplio espectro a } \\
\text { base de metronidazol, } \\
\text { imipenem y } \\
\text { gentamicina } \\
\text { intravenosa. }\end{array}$ & $\begin{array}{l}\text { Resolución clínica. } \\
\text { A los } 6 \text { meses } \\
\text { presencia de lesiones } \\
\text { cicatriciales en } \\
\text { pulmón. }\end{array}$ \\
\hline $2010^{[9]}$ & $43 / M$ & Diabetes no controlada. & $\begin{array}{l}\text { Cultivo bacteriano } \\
\text { con crecimiento de } \\
\text { Haemophilus influenzae. }\end{array}$ & $\begin{array}{l}\text { Solo cirugía } \\
\text { (lobectomía). }\end{array}$ & No reportado. \\
\hline $2011^{[10]}$ & $23 / F$ & Síndrome de Down & $\begin{array}{l}\text { Presencia de cocos } \\
\text { grampositivos en biopsia } \\
\text { de parénquima pulmonar. }\end{array}$ & $\begin{array}{l}20 \text { días con } \\
\text { meropenem y } \\
\text { vancomicina. }\end{array}$ & Resolución clínica. \\
\hline $2013^{[11]}$ & $56 / \mathrm{M}$ & Fumador crónico. & $\begin{array}{l}\text { Las tinciones especiales } \\
\text { fueron negativas para } \\
\text { bacilos ácido alcohol } \\
\text { resistentes, hongos } \\
\text { y no se identificaron } \\
\text { los gránulos típicos de } \\
\text { actinomicosis. }\end{array}$ & $\begin{array}{l}\text { Empíricamente: } \\
\text { ceftriaxona y } \\
\text { azitromicina por } 2 \\
\text { semanas. Más cirugía } \\
\text { (lobectomía). }\end{array}$ & $\begin{array}{l}\text { Alta } 20 \text { días } \\
\text { poslobectomía. A los } \\
6 \text { meses resolución } \\
\text { completa. }\end{array}$ \\
\hline
\end{tabular}

Nota: La tabla está conformada por casos humanos de botriomicosis de origen primario en pulmón registrados en MEDLINE. Los casos están ordenados según su año de reporte y se adjunta el número de referencia para su revisión. 


\section{REFERENCIAS BIBLIOGRÁFICAS}

1. Paz HL, Little BJ, Ball WC Jr, Winkelstein JA. Primary pulmonary botryomycosis. A manifestation of chronic granulomatous disease. Chest. 1992;101(4):1160-2.

2. Multz AS, Cohen R, Azeuta V. Bacterial pseudomycosis: a rare cause of hemoptysis. Eur Respir J. 1994;7(9):1712-3.

3. Bersoff-Matcha SJ, Roper CC, Liapis H, Little JR. Primary Pulmonary Botryomycosis: Case Report and Review. Clin Infect Dis. 1998;26(3):620-4.

4. Katapadi K, Pujol F, Vuletin JC, Katapadi M, Pachter BR. Pulmonary botryomycosis in a patient with AIDS. Chest. 1996;109(1):276-8.

5. Tuggey JM, Hosker HS, Da Costa P. Primary pulmonary botryomycosis: a late complication of foreign body aspiration. Thorax. 2000;55(12):1068-9.

6. Hodgson R, Blackmore SA, Clarke CP. Pulmonary botryomycosis: A difficult diagnosis in the preoperative patient. J Thorac Cardiovasc Surg. 2005;130(3):924-5.

7. Cubilla E, Guzmán A, González A, Mendoza G, Aguilar G, García $\mathrm{T}$, et al. Botriomicosis cutánea. Un caso infantil y uno adulto. Dermatología CMQ. 2010;8(3):187-91.
8. González D, Fernández R, de la Torre M, Delgado M, Paradela M, García J, et al. Caso clínico: Botriomicosis Pulmonar. Pneuma. 2008;4(3):117-9.

9. Tung A, Ngai J, Ng S, Ko F, Hui D. Pulmonary botryomycosis: a bloody cough with a bloody twist. In: American Thoracic Society 2010 International Conference. Fourth edition. New Orleans: American Thoracic Society; May 14-19, 2010. p. A6864-A6864.

10. Faisal H, Radwan A, Ansari N. Primary pulmonary botryomycosis presenting with septic shock and acute lung injury. BMJ Case Rep. 2011;2011. pii: bcr1120103527.

11. Alavi A, Aghajanzadeh M, Asgari K, Massahnia S. Pulmonary Botryomycosis Mimicking Bronchogenic Carcinoma of the Lung. Tanaffos. 2013;12(3):62-4.

12. Prieto-Granada CN, Lobo AZC, Mihm MC. Skin Infections [Internet]. En: Kradin RL, editor. Diagnostic Pathology of Infectious Disease. New York: W.B. Saunders; 2010. 519-616.

13. García A, García E, Hernández A, Ruiz J, Yagüe G, Herrero J, et al. Bacteriemias por Escherichia coli productor de betalactamasas de espectro extendido (BLEE): significación clínica y perspectivas actuales. Rev Esp Quimioter. 2011;24(2):57-66.

\section{Ahora puede enviar sus artículos para Acta Médica Peruana en nuestro Open Journal System:}

www.amp.cmp.org.pe

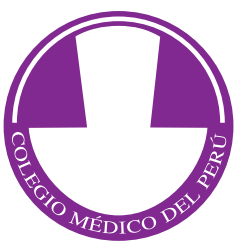

